\title{
O DESENVOLVIMENTO RURAL SOB O OLHAR DE UM NOVO PARADIGMA: O CASO DO ESTADO DO RIO DE JANEIRO
}

\author{
Alcimar Chagas Ribeiro ${ }^{1}$ \\ ORCID: https://orcid.org/0000-0002-7954-7118 \\ Recebido em:12/04/2021 \\ Publicado em:30/06/2021
}

\begin{abstract}
RESUMO
A crise econômica no estado do Rio de Janeiro gera reflexões sobre possíveis alternativas à atividade petrolífera. As expectativas do setor, sem estratégias efetivas para absorção das externalidades positivas, se tornaram em frustração com o encolhimento produtivo da Bacia de Campos na última década. $O$ investimento no setor agropecuário é indicado pelas lideranças sem um diagnóstico mais abrangente. É nesse sentido a contribuição do presente trabalho, cujo objetivo é desenvolver uma análise sistematizada da economia rural fluminense a luz dos fundamentos característicos da economia de baixa densidade conceituada pela OECD, na percepção de especialistas do setor. Os resultados são preocupantes, apesar de iniciativas pontuais exitosas.
\end{abstract}

PALAVRAS CHAVE: Desenvolvimento rural; Competitividade regional; Novo paradigma rural.

\section{RURAL DEVELOPMENT UNDER THE PERSPECTIVE OF A NEW PARADIGM: THE CASE OF THE STATE OF RIO DE JANEIRO}

\begin{abstract}
The economic crisis in the state of Rio de Janeiro generates reflections on possible alternatives to oil activity. The sector's expectations, without effective strategies to absorb positive externalities, turned to frustration with the production shrinkage of the Campos Basin in the last decade. Investment in the agricultural sector is indicated by leaders without a more comprehensive diagnosis. It is in this sense the contribution of the present work, whose objective is to develop a systematized analysis of the rural economy of Rio de Janeiro in the light of the characteristic foundations of the low-density economy considered by the OECD, in the perception of specialists in the sector. The results are worrisome, despite successful specific initiatives.
\end{abstract}

KEY WORDS: Rural development; Regional competitiveness; New rural paradigm.

\footnotetext{
${ }^{1}$ Economista, Doutor em Engenharia de Produção e Pós - Doutorado em Economia. Professor da Universidade Estadual do Norte Fluminense darcy Ribeiro - UENF. E-mail: alcimar@uenf.br
} 


\section{INTRODUÇÃO}

$\mathrm{O}$ advento da pandemia do novo corona vírus que assolou o mundo e deprimiu as bases da estrutura econômica global expandiu a desigualdade social com aprofundamento do desemprego e pobreza (RIBEIRO E MAROUVO, 2020). É nesse contexto que o território fluminense, com seus traços de heterogeneidade, vê escancarar problemas econômicos de natureza diversas. O estado produtor de petróleo, sede de um dos maiores portos do mundo e detentor de ricos recursos naturais, não conseguiu se apropriar das externalidades positivas dos grandes projetos implementados (RIBEIRO e HASENCLEVER, 2019).

Por outro lado, as rendas oriundas de royalties e participações especiais da exploração de petróleo, transferidas pela Agência Nacional de Petróleo (ANP) nos anos 2000, não foram capazes de transformar o estado a uma condição de compatibilidade com os investimentos públicos e privados fixados no território (NAZARETH, P. et al. 2018).

Com o declínio esperado da produtividade da produção de petróleo e a queda acentuada das rendas de royalties e participações especiais, a busca de alternativas econômicas passou a tomar conta das agendas das discussões econômicas entre as lideranças políticas, empresários e atores da sociedade civil (NUPERJ, 2020).

Com o olhar para o passado, logo vem o resgate da importância histórica do setor agropecuário como alternativa à atividade petrolífera, cuja riqueza de outrora dificilmente retornará, até porque os campos maduros exigem esforços de investimento distante do interesse da Petrobras, conforme indicado no seu plano estratégico para 2021 a 2025 (PETROBRAS, 2020).

Entretanto, a visão sobre o setor agropecuário parece não ter avançado com o tempo. Muito se discute sobre possibilidades diversas como agroindústria, agronegócios, sem, portanto, indicar como operacionalizar. A percepção é de que os diagnósticos existentes não contribuem para um planejamento adequado da construção de novo modelo de desenvolvimento rural com perspectivas de sucesso.

Tendo isso em vista, o presente artigo traz exatamente essa preocupação e objetiva entender a economia rural do estado do Rio de Janeiro, tomando como base o "Novo Paradigma Rural", criado pela OCDE para apoiar a economia rural dos países da Europa (OECD, 2006 e 2019).

Buscar-se-á responder as seguintes questões: (i) se a economia rural do estado do Rio de Janeiro apresenta características equivalentes a uma economia de baixa densidade, 
segundo conceito da OCDE, e em que grau; e (ii) se a economia rural do estado tem respondido aos parâmetros do Novo Paradigma Rural da OCDE, e em que grau.

\section{BREVE DISCUSSÃO SOBRE A EVOLUÇÃO DOS MODELOS DE DESENVOLVIMENTO RURAL}

Revisitando o desenvolvimento rural neo-endógeno, Gkartzios e Lowe (2019) relatam que a busca por uma teoria do desenvolvimento rural mais abrangente é longa e faz um recorte no pós-guerra para explicar o modelo exógeno de desenvolvimento rural. Segundo os autores, esse modelo se constituiu como frágil por tratar as áreas rurais como dependentes técnica, cultural e economicamente, tendo como função fornecer alimentos para as populações urbanas em constante expansão.

O modelo exógeno de desenvolvimento rural, segundo Lowe, et.al. (1998), apresenta as seguintes características:

\begin{tabular}{|l|l|}
\hline Princípio chave & Economia de escala e concentração. \\
\hline Força dinâmica & $\begin{array}{l}\text { Polos de crescimento urbano, com as } \\
\text { principais forças do desenvolvimento } \\
\text { provenientes de áreas rurais de fora. }\end{array}$ \\
\hline Função das áreas rurais & $\begin{array}{l}\text { Alimentos e outras produções primárias para } \\
\text { a expansão da econômica urbana. }\end{array}$ \\
\hline Principais problemas da área rural & $\begin{array}{l}\text { Baixa produtividade e concentração na } \\
\text { periferia. }\end{array}$ \\
\hline Foco do desenvolvimento rural & $\begin{array}{l}\text {-Industrialização e especialização agrícola. } \\
\text {-Incentivo à mobilidade de mão de obra e } \\
\text { capital. }\end{array}$ \\
\hline
\end{tabular}

Fonte: Lowe, et.al. (1998)

Apesar de benefícios gerados em alguns lugares como aumento da taxa de emprego, melhoria na tecnologia e comunicação, o modelo recebeu críticas em função da sua dependência por investimento externo, onde os lucros do desenvolvimento são frequentemente exportados e não fixados localmente. Um outro aspecto é a natureza não participativa do modelo que pode criar déficit democrático (WOODS, 2005).

As críticas ao modelo exógeno de desenvolvimento rural foram fundamentais para a sistematização do modelo endógeno que traz a distinção entre os atores internos e externos no controle do processo de desenvolvimento. O modelo endógeno privilegia a ação local.

A abordagem endógena na visão de Ray (1997), tem três características fundamentais: 
$>$ A atividade de desenvolvimento é definida dentro de um quadro territorial e não setorial, com a escala do território sendo menor do que a nação;

A atividade econômica e outras atividades de desenvolvimento são restruturadas de forma a maximizar a retenção de benefícios dentro do território local, valorizando os recursos locais tanto físico quanto humano;

O desenvolvimento é contextualizado como foco nas necessidades, capacidades e perspectivas de pessoas locais;

Baseado nos mesmos principais Lowe (1998) resume o modelo de desenvolvimento rural, conforme a seguir:

\begin{tabular}{|l|l|}
\hline Princípio chave & $\begin{array}{l}\text { Os recursos específicos de uma área } \\
\text { (naturais, humanos e culturais) detém a chave } \\
\text { para o seu desenvolvimento sustentável. }\end{array}$ \\
\hline Força dinâmica & Iniciativa e empreendimento local. \\
\hline Função das áreas rurais & Economias de serviço diversas. \\
\hline Principais problemas da área rural & $\begin{array}{l}\text { A capacidade limitada de áreas e grupos } \\
\text { sociais para participar em atividade } \\
\text { econômica e de desenvolvimento. }\end{array}$ \\
\hline Foco do desenvolvimento rural & $\begin{array}{l}\text {-Capacitação (habilidades, instituições e } \\
\text { infraestrutura). } \\
\text {-Superando a exclusão social. }\end{array}$ \\
\hline
\end{tabular}

Fonte: Lowe (1998)

O modelo de desenvolvimento rural endógeno representa um passo adiante do exógeno com avanços inegáveis, porém experiências reais de sua aplicação demonstraram problemas. Dentre eles, dificuldade com a participação, elitismo, limitações da ação local e controle. Preocupações diversas no contexto europeu foram expressas por diferentes cientistas sociais entre eles Kovach (2000), Osti (2001) e Shortall (2008), como, por exemplo, a tendência para iniciativas endógenas de desenvolvimento para favorecer aqueles que já são poderosos e articulados. Nesse caso, o foco no combate à desigualdade perde força, já que os favorecidos gozam de uma maior capacidade de ação e de engajamento com a iniciativa.

Considerando ainda a rigidez em relação à visão que separa o local do ambiente externo e da importância sobre o entendimento do papel da globalização, o modelo de desenvolvimento rural endógeno abre espaço para o modelo neo-endógeno, estruturado a partir de experiências empíricas onde é possível o ajustamento das dificuldades encontradas.

Com base nas críticas ao modelo endógeno, Gkartzios e Scott (2014), estruturam o modelo neo-endógeno de desenvolvimento rural a partir dos seguintes elementos: 


\begin{tabular}{|c|c|}
\hline Princípio chave & $\begin{array}{l}\text { Justiça socioespacial e equilíbrio das } \\
\text { necessidades locais ao mesmo tempo } \\
\text { competindo por pessoas, recursos, } \\
\text { habilidades e capital extra locais. }\end{array}$ \\
\hline Força dinâmica & $\begin{array}{l}\text { Promover uma nova relação urbano rural e } \\
\text { local global por meio de governança } \\
\text { inclusiva e arranjos multissetorial e } \\
\text { multiescalar. }\end{array}$ \\
\hline Função das áreas rurais & $\begin{array}{l}\text { - Sustentar os meios de subsistência, ao } \\
\text { mesmo tempo que mantém o capital natural; } \\
\text { - Um mosaico de funções produtivistas } \\
\text { reemergentes e uso consumistas (incluindo } \\
\text { habitação, serviço). }\end{array}$ \\
\hline Principais problemas da área rural & $\begin{array}{l}\text { - Campos exclusivos; } \\
\text { - Desregulamentação neoliberal versus apatia } \\
\text { política e falta de regulamento; } \\
\text { - Desafios da mudança climática; } \\
\text { - Crise econômica. }\end{array}$ \\
\hline Foco do desenvolvimento rural & $\begin{array}{l}\text { - Criação de lugares e bem-estar da } \\
\text { comunidade; } \\
\text { - Construir locais rurais resilientes; } \\
\text { - Lidar com a nova política de austeridade; } \\
\text { - Lidar com geografias emergentes de } \\
\text { exclusão e mobilidade desencadeada por } \\
\text { crises econômicas; } \\
\text { - Perceber e valorizar alternativas de } \\
\text { desenvolvimento (especialmente não liberal) } \\
\text { em tempos de crise. }\end{array}$ \\
\hline $\begin{array}{l}\text { Foco no rural } \\
\text { Desenvolvimento de pesquisa }\end{array}$ & $\begin{array}{l}\text { Análise comparativa internacional, diálogos e } \\
\text { aulas compartilhadas (inclusivas, mas não } \\
\text { exclusivas dos contextos EUA/UA). }\end{array}$ \\
\hline
\end{tabular}

Fonte: Gkartzios e Scott (2014).

A despeito de modelos utilizados, o desenvolvimento em comunidades rurais na Coreia é analisado por Kim (2020), indicando que o projeto de aldeia conjunta que começou com suporte da mesma organização externa, resultou em resultados diferentes, em função das condições e circunstância internas das aldeias. Um primeiro movimento que começou a desenvolver vilas sob a influência do movimento de agricultura ambientalmente amigável com suporte fornecidos por organizações locais para aumentar o desempenho econômico, foi um fracasso e os residentes mudaram para buscar atividades por conta própria. Já um segundo movimento de cooperação entre os moradores foi fortalecido na implementação do projeto de apoio das agências externas. Segundo o autor, os laços comunitários e a identidade foram fortalecidos, já que os problemas foram resolvidos por meio da cooperação entre os residentes no processo de promover o projeto da aldeia. Um caso típico de boa estrutura de capital social, onde o comportamento de cooperação e regras de reciprocidades tendem a superar os dilemas coletivos nas comunidades cooperativas (PUTNAM, 2005). 
Logo, o autor indica que a abordagem neo-endógena de desenvolvimento utilizando apoio externo com base na rede cooperativa interna entre os moradores deve ser um método muito útil para o desenvolvimento rural nas sociedades contemporâneas.

Na discussão sobre desenvolvimento rural, Shortall (2012) afirma que apesar das inúmeras contribuições das práticas neo-endógenas no contexto da Europa e em outros lugares, ainda permanece ausente nesses debates a reflexão sobre o papel da academia e, em particular, dos cientistas sociais na produção de discursos sobre a temática. $O$ autor complementa que lutas de poder em relação a formas concorrentes de conhecimento não é uma proposta nova no domínio rural.

Ainda no esforço de reflexão sobre desenvolvimento rural Biczkowski (2020) avaliou o projeto LEADER no contexto dos recursos que determinam as oportunidades de desenvolvimento, considerando um elemento complementar a discussão corrente pela ótica geográfica e espacial. Segundo o autor, a abordagem tem contribuído substancialmente para a mobilização de recursos locais em áreas rurais com aumento do número de Grupos de Ação Local (GALs).

LEADER, segundo Gkartzios (et. al.), coloca no centro do processo de desenvolvimento os grupos autônomos de ação local (GALs), trabalhando em parceria nos setores público, privado e voluntário. Os elementos essenciais desta abordagem para o desenvolvimento rural são identificados por pesquisadores como Moseley (1997) e Ray (2000) e incluem: foco em um territorial integrado; o uso de recursos locais; e contextualização local por meio da participação ativa do público.

Biczkowski (op. cit.) ainda traz indicações importantes sobre o desenvolvimento rural. Segundo o autor, as políticas implementadas devem originar-se do potencial endógeno existente no território, onde a inclusão de recursos locais no processo de desenvolvimento como princípio fundamental postula claramente o (neo) desenvolvimento endógeno. Essa abordagem integra os fatores internos específicos de uma determinada área, ao potencial dos recursos disponíveis dentro da comunidade local que moldam o meio ambiente. Nesse contexto, um dos principais elementos do desenvolvimento econômico é a orientação para as capacidades, habilidades, cooperação e as perspectivas da população que são expressas por meio de seu envolvimento em propor e implementar o desenvolvimento de atividades (RAY, 2000, 2006).

Nesse contexto, a OECD estrutura um modelo de desenvolvimento rural denominado " $\mathrm{O}$ Novo Paradigma Rural", com vistas a combater os problemas nas atividades agrárias, especialmente nos países da Europa. 


\section{O NOVO PARADIGMA RURAL}

A redução do emprego na economia rural tornou-se um grave problema no mundo. Nas economias rurais da Europa tal fato ficou evidente entre as décadas de 1980 e 1990, motivando esforços para a transformação estrutural dessas economias através do crescimento econômico e oportunidade de emprego (OCDE, 2006). Esse processo foi a base da construção de um Novo Paradigma, cuja abordagem traz o local como base do desenvolvimento rural.

As evidências se consubstanciaram na condição de que nas economias das regiões rurais da OCDE a agricultura é frequentemente uma atividade marginal. Na Europa a dispersão no desempenho sugere que as economias rurais enfrentam desafios particulares ligados a fatores como a diversificação imitada das atividades econômicas, carência de acessibilidade necessária, falta de massa crítica e envelhecimento da população, em parte, por conta da emigração de jovens.

A nova visão traz um conceito que posiciona a política rural como estratégia de investimento para promoção da competitividade nas zonas rurais com mudança dos programas de subsídios típicos destinados aos setores. A crise de 2008 acelerou a necessidade urgente da busca de crescimento econômico e oportunidade de emprego em regiões de baixa densidade (OCDE, 2009).

As características impostas às economias de baixa densidade correspondem a alguns elementos, tais como: 1. distância física para os principais mercados, o que ampliam os custos de transporte e dificulta a falta de conectividade em rede; 2 . frágil competitividade econômica, em função do mercado de trabalho estrito e da dependência de fontes de crescimento exógenas; 3. estrutura econômica específica, ocasionada por produção concentrada em poucos setores, onde a maioria dos empregos são concentrados em serviços de baixa renda, fabricação em ciclo de produto maduro e baixo capital humano; e 4. qualidade de vida no espaço rural,dependente de investimento em saúde, investimento em educação e infraestrutura (água, energia, saneamento e comunicação).

O Novo Paradigma Rural pode ser melhor entendido através da sistematização a seguir: 


\begin{tabular}{|l|l|l|}
\hline & Paradigma Velho & Paradigma Novo \\
\hline Objetivos & $\begin{array}{l}\text { Equalização ou abordagem do } \\
\text { direito focado na renda, } \\
\text { competitividade da fazenda. }\end{array}$ & $\begin{array}{l}\text { Competitividade das áreas } \\
\text { rurais, valorização de recursos } \\
\text { não utilizados. }\end{array}$ \\
\hline Alvo chave & Baseada no setor. & $\begin{array}{l}\text { Vários setores da economia rural } \\
\text { (turismo rural, manufatura, } \\
\text { indústria TICs, etc.). }\end{array}$ \\
\hline Principais ferramentas & Subsídios. & $\begin{array}{l}\text { Investimento. } \\
\text { Principais atores }\end{array}$ \\
$\begin{array}{l}\text { Governos os níveis de governo } \\
\text { agricultores. nacionais }\end{array}$ & $\begin{array}{l}\text { (supranacional, nacional, } \\
\text { regional e local), várias partes } \\
\text { interessadas locais (público, } \\
\text { privado, ONGs). }\end{array}$ \\
\hline
\end{tabular}

Fonte: OECD (2006), The New Rural Paradigm, OECD Publishing, Paris

\section{ASPECTOS METODOLÓGICOS}

A partir da estrutura conceitual apresentada, o trabalho objetiva construir um diagnóstico ampliado da economia rural do estado do Rio de Janeiro baseando-se nos principais fundamentos do modelo da OCDE “O Novo Paradigma Rural” de 2006. Buscar-seá responder as seguintes indagações: (i) se a economia rural do estado do Rio de Janeiro apresenta características equivalentes a uma economia de baixa densidade, segundo conceito da OCDE, e em que grau; (ii) se a economia rural do estado tem respondido aos parâmetros do Novo Paradigma Rural da OCDE, e em que grau.

O primeiro bloco reúne as características da economia de baixa densidade da OCDE: 1. Distância física para os principais mercados, com impactos no aumento dos custos de transporte e na dificuldade de conectividade em rede; 2. Competitividade econômica, caracterizada por fonte de crescimento exógeno e mercado de trabalho estreito; 3. Estrutura econômica específica, baseada na concentração de poucos setores, empregos em serviço de baixa renda, fabricação em ciclo de produto maduro, baixo volume de capital humano e; 4. Qualidade de vida no espaço rural, a partir de investimento em saúde, educação e em infraestrutura de saneamento básico, água, energia e comunicação.

O segundo bloco reúne as estratégias fundamentais no contexto do "Novo Paradigma Rural" da OECD, que serão utilizadas como padrão de eficiência para verificar o quanto a economia rural do estado do Rio de Janeiro se enquadra ou não, segundo uma escala (inexiste, baixo, médio, elevado e muito elevado).

Com uma abordagem centrada nas pessoas, o primeiro elemento considera, além dos objetivos econômicos, os objetivos sociais e os ambientais. O segundo elemento consiste na capacidade de entendimento sobre as diversidades e os desafios rurais. O terceiro elemento, 
está na capacidade de preparo das áreas para adotar tecnologias digitais. O quarto elemento, tem foco no esforço para aumento da produtividade com agregação das atividades. O quinto elemento consiste no apoio a adaptação demográfica e os serviços públicos de qualidade. $\mathrm{O}$ sexto elemento no apoio a facilitação a transição para a economia neutra para o clima.

A obtenção das respostas se dará através da sistematização da percepção de cinco especialistas consultados, seguido da análise de dados do censo agropecuário de 1995, 2006 e 2017, com reforço da análise dos indicadores de lavouras temporária e permanente, além da análise dos dados de pecuária leiteira (IBGE, 2019).

\section{PERCEPÇÃO DE ESPECIALISTAS SOBRE A ECONOMIA RURAL FLUMINENSE}

A busca para as respostas às indagações sugeridas na introdução desse artigo, nesse primeiro momento, se deram através da percepção de cinco especialistas renomados no assunto, os quais identificamos como: Rogério Ribeiro Castro, engenheiro agrícola, mestre em Engenharia de Produção e servidor da Universidade Estadual do Norte Fluminense Darcy Ribeiro - UENF; João Gomes de Siqueira, doutor em Ciência Animal, professor da UENF e diretor presidente do Comitê do Baixo Paraíba do Sul e Itabapoana; José Carlos Mendonça, doutor em Produção Vegetal e professor da UENF; José Luiz Viana da Cruz, doutor em Ciências Socias e professor da UFF e Almy Junior Cordeiro de Carvalho, doutor em Produção Vegetal e professor titular da UENF e secretário de agricultura do município de Campos dos Goytacazes.

As entrevistas evoluíram na forma de diálogo, considerando dois blocos de questões citados na metodologia. No esforço de sistematização dos resultados, observa-se consenso entre os pesquisadores sobre os temas levantados, com poucas variações que serão comentadas.

\section{Bloco 1 - Percepção sobre a presença de características da economia de baixa densidade na economia rural fluminense}

No primeiro elemento definido como distância física dos principais mercados, com impactos no aumento dos custos de transporte e na dificuldade de conectividade em rede, a percepção dos pesquisadores foi consensual de elevados custos e baixo padrão de conectividade em rede. Entretanto, algumas situações pontuais são importantes, especialmente, nas falas de Viana e Mendonça, que apontam casos de sucesso, por conta de 
melhor organização e, consequentemente, melhor informação. Tendo o Ceasa no Rio de Janeiro como ponto de escoamento, os núcleos mais organizados tiram proveito de possível valorização de produtos e, nesses casos, o custo pode ser diluído. Como exemplos de nichos importantes, são citados o cinturão verde em Nova Friburgo e entorno e a produção de produtos orgânicos em Teresópolis, dirigido pelo ator de televisão Marcos Palmeira. Carvalho insere na discussão exemplos de sucesso da serra do Espírito Santo, para externa o que considera o principal desafio da economia rural fluminense. Na verdade, são pontos fora da curva, que não descaracterizam o diagnóstico de forte atraso da economia rural do estado do Rio de Janeiro.

No segundo elemento, que é a competitividade econômica, caracterizada por fonte de crescimento exógeno e mercado de trabalho estreito, a percepção dos pesquisadores está muito próxima. Entendem que a fragilidade do crescimento econômico no setor torna o mercado de trabalho estreito. Gomes chama atenção para iniciativas tanto de crédito, como tecnológicas, sem planejamento, assim como, pontuais iniciativas quase sempre individuais que não se sustentam.

Mirando o exemplo da estrutura de investimento para a produção de produtos orgânicos citado acima, a observação é de que os maiores investidores trazem recursos de capital de fora da região, maximizam resultados e transferem parcela relevante para as regiões centrais de origem dos mesmos investidores. Quanto ao mercado de trabalho estreito, a percepção é de elevado e muito elevado, fato que de alguma maneira está de acordo com a evolução dos nichos de sucesso de motivação exógena.

Olhando para as regiões Norte e Noroeste Fluminense, Carvalho concentra muitos dos problemas na condição de ausência da posse de terra, que pode chegar próximo de $80 \%$ nas pequenas propriedades. O pesquisador identifica ainda, como exemplo de crescimento exógeno, iniciativas importantes de unidades de processamento de pescado na região de Barra Furado e Farol de São Thomé em Campos dos Goytacazes, onde o investimento de capital e até partes relevantes da matéria prima tem origem externa. Nesse caso, fica impossível avançar em projetos mais robustos por iniciativas internas e, consequentemente, ampliar o mercado de trabalho.

No terceiro elemento, estrutura econômica especifica, baseada na concentração de poucos setores, empregos em serviço de baixa renda, fabricação em ciclo de produto maduro, baixo volume de capital humano, a percepção dos especialistas é de elevado e muito elevado. A diversificação de atividades agropecuárias é um problema no estado. A concentração como no caso da cana-de-açúcar tem fortes impactos na renda do trabalho. O baixo nível de 
processamento industrial a partir do setor, por sua vez, apresenta baixo padrão tecnológico com atuação em ciclo de produto maduro. Quanto ao volume de capital humano, Mendonça chama atenção para o importante estoque de recursos humanos, especialmente, lotados nas universidades e centro de pesquisas do estado do Rio de Janeiro. Entretanto, não se pode ignorar uma questão paradoxal que é a relevante rede de ensino e pesquisa agropecuária no território fluminense e, do outro lado, uma empobrecida economia rural, em seu aspecto mais geral.

No quarto elemento qualidade de vida no espaço rural, a partir de investimento em saúde, educação e investimento em infraestrutura de saneamento básico, água, energia e comunicação, a percepção dos especialistas é consensual no que diz respeito a um baixo padrão da qualidade de vida no espaço rural. Carvalho, Viana e Castro relatam inúmeras dificuldades da educação na área rural, enquanto Gomes cita casos de mobilização de moradores rurais no transporte de doentes para atendimento na cidade, o que mostra a fragilidades desses serviços na área rural.

\section{Bloco 2 - Estratégias fundamentais no contexto do "Novo Paradigma Rural" da OECD}

A análise desse bloco levou em consideração os elementos fundamentais do "Novo Paradigma Rural" da OECD, a saber: dos objetivos econômicos aos sociais e ambientais; capacidade de entendimento sobre as diversidades e os desafios rurais; capacidade de preparo das áreas para adotar tecnologias digitais; esforço para aumento da produtividade com agregação das atividades; apoio a adaptação demográfica e os serviços públicos de qualidade; facilitação a transição para uma economia neutra para o clima.

A percepção dos pesquisadores sobre iniciativas presentes da economia rural fluminense no contexto do modelo denominado "Novo Paradigma Rural" foi consensual, identificando uma condição de baixo padrão para todos os elementos. Como já indicado anteriormente, a economia rural fluminense apresenta um forte perfil em compatibilidade com a economia de baixa densidade, norteada pela falta de planejamento integrado e dependente de iniciativas individuais. Os custos elevados por propriedade, a dificuldade de informação, de crédito, a baixa capacidade de gestão tem sido um grave problema. Por outro lado, faltam iniciativas de âmbito coletivo e sobram discursos políticos que não se sustentam. O baixo rendimento das atividades fixadas internamente empobrece a capacidade de consumo da população envolvida que ainda sofre com o baixo padrão de investimento em infraestrutura, saúde e educação. Com isso, a vida no campo materializa um baixo padrão de sobrevivência e empurra os jovens quase sempre com baixa escolaridade para as cidades. 


\section{ALGUNS INDICADORES IMPORTANTES SOBRE O SETOR AGROPECUÁRIO FLUMINENSE}

Os dados do setor agropecuário fluminense mostram um crescimento do número de estabelecimentos. O censo de 1995 indicou 53.680 unidades, o censo de 2006 indicou 58.493 e o censo de 2017 indicou 65.224 unidades, o que equivale a um crescimento relativo de $21,5 \%$ em um pouco mais de duas décadas.

O pessoal ocupado apresentou uma leve variação. Segundo o censo de 1995 o setor contava com 174.274 trabalhadores, número que foi reduzido para 157.696 trabalhadores no censo de 2006. Já no censo de 2017 foi contabilizado um crescimento desse estoque para 178.583 trabalhadores no setor. Apesar do crescimento de 21,5\% no número de estabelecimentos, o pessoal ocupado cresceu 2,5\% em 2017 com base em 1995.

Para uma visão mais atualizada recorremos a pesquisa agrícola municipal e a pesquisa pecuária municipal do IBGE. Analisando os anos de 1995, 2006, 2017 e 2019, da lavoura temporária e permanente do estado, observa-se uma queda acentuada da área colhida no período. Em 1995, a área colhida somou 285.387 hectares, caindo para 244.654 hectares em 2006, reduzindo ainda mais para 113.891 hectares em 2017 e reduzindo levemente para 113.309 hectares em 2019. Já os valores da produção deflacionados pelo IPC-DI-FGV caíram de $\mathrm{R}$ \$2,1 bilhões em 1995 para $\mathrm{R}$ \$1,4 bilhão em 2006, com nova queda para $\mathrm{R}$ \$1,3 bilhão em 2017 e um leve aumento para R\$1,5 bilhão em 2019.

Com base nesses dados, apurou-se a produtividade da atividade agrícola (reais por hectare) no estado, conforme figura a seguir.

Figura 1 - Produtividade real na agricultura fluminense

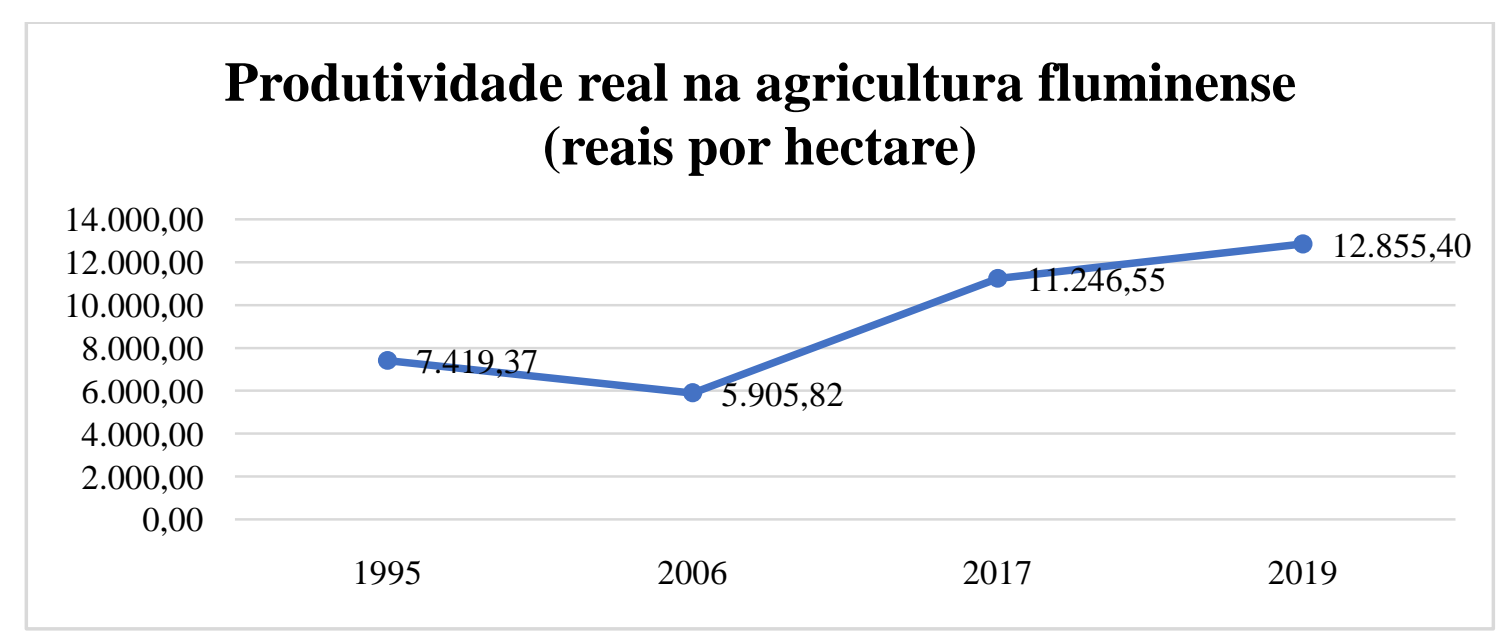

Fonte: Elaboração própria com base no IBGE. 
Em 1995 a produtividade atingiu $\mathrm{R} \$ 7.419,37$ (valores de 2019) por hectare, caindo para $\mathrm{R} \$ 5.905,82$ uma década depois. Um fato que chama a atenção é a forte concentração no cultivo da cana-de-açúcar nesses dois momentos. Em 1995 a área utilizada pela cultura era equivalente a 56,69\% da área total, que foi ampliada para 62,05\% de participação em 2006.

Nos períodos seguintes, pode-se observar uma forte evolução da produtividade que chegou a $\mathrm{R} \$ 11.246,55$ em 2017 e $\mathrm{R} \$ 12.855,40$ em 2019. Nesses períodos, a área colhida da cultura de cana-de-açúcar sofreu forte retração. Em 2017 a área correspondente atingiu 47,04\% e em 2019 atingiu 47,22\% da área total.

Parece ficar evidente que o avanço do cultivo da cana-de-açúcar, cujas características são bem conhecidas, ou seja, produtividade baixa, dependência de clima favorável, ausência de controle sobre a formação do preço, pressão trabalhista e ambiental, etc., tende a derrubar a produtividade total do setor. Por outro lado, o encolhimento da área de cana-de-açúcar, além do uso para pecuária, abre espaço para uma maior diversificação de culturas que sofrem menos com a mazelas indicadas acima e conseguem preços melhores no mercado.

O quadro traçado parece se confirmar nos períodos seguintes, quando diminui a pressão do cultivo da cana-de-açúcar. Em 2019 verificou-se uma melhor diversificação com o avanço de culturas como: café, mandioca, tomate, laranja, coco da baia, banana e abacaxi, dentre outras, aumentado fortemente o valor da produção.

Uma leitura final sobre as atividades de lavoura temporária e permanente do estado do Rio de Janeiro apresenta a seguinte situação: a queda de 172.078 hectares em 2019 com base em 1995, ou o equivalente a 60,3\% no período, potencializou a produtividade medida pela receita monetária por hectare nos anos de 2017 e 2019. A figura a seguir apresenta a produtividade das unidades da federação na região sudeste do país. 
Figura 2 - Produtividade agrícola na região sudeste

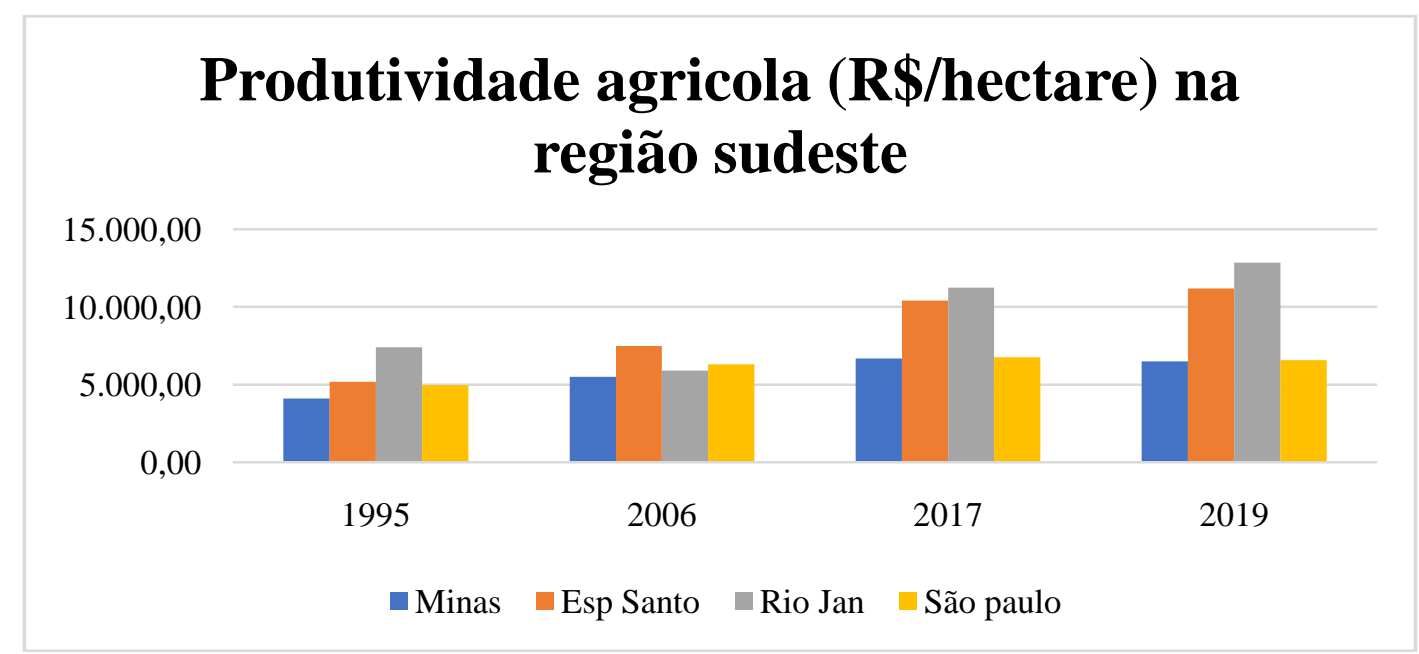

Fonte: Elaboração própria, com base no IBGE.

Uma lição importante que pode-se tirar é que o estado do Rio de Janeiro mostra um potencial importante a ser explorado. Apesar das frágeis condições do contexto da economia rural diagnosticada com base no Novo Paradigma Rural da OECD, onde as carências são acentuadas, a produtividade agrícola nos últimos anos vem melhorando e sobressai-se na comparação com os outros estados da região sudeste. O Rio de Janeiro apresentou uma produtividade de $\mathrm{R} \$ 12.855,40$ por hectare em 2019 , a maior da região sudeste, seguido pelo Espirito Santo com uma produtividade de R $\$ 11.246,55$ no mesmo ano. Com valores bem abaixo, São Paulo tem uma produtividade de $\mathrm{R} \$ 6.570,89$ e Minas Gerais tem uma produtividade de $\mathrm{R} \$ 6.496,70$ no ano investigado.

Em uma outra análise, observamos que a pecuária leiteira mostra uma certa estabilidade no tempo. Em 1995 a produção leiteira no estado gerou 432,4 milhões de litros de leite, avançando para 468,2 milhões de litros em 2006, caindo levemente para 466,2 milhões de litros em 2017 e voltando a cair para 431,9 milhões de litros em 2019. A produção mais atual de 2019 é menor 0,1\% em relação a produção de 1995.

O número de vacas ordenhadas também não apresentou grandes mudanças no período analisado. Em 1995 o estado tinha 394,5 mil vacas ordenhadas, crescendo levemente para 395,1 vacas em 2006, caindo para 359,5 vacas em 2017 e voltando a cair para 331,1 vacas em 2019. O número do último plantel é menor 16,1\% em relação ao plantel de 1995.

Apesar da queda mais acentuada no número de vacas ordenhadas, a produtividade litro de leite / vaca / ano, apresentou uma pequena melhora. Em 1995 a produtividade era de 1.096 litros, chegando em 2006 a 1.185 litros, avançando em 2017 para 1.297 litros e avançando, mais um pouco, em 2019 para 1.304 litros / vaca / ano. 
Se o estado do Rio de Janeiro tem destaque na produtividade agrícola na região sudeste, na pecuária leiteira a situação é bem diferente. A figura a seguir apresenta a produtividade leiteira dos estados em 2019.

Figura 3 - Produtividade leiteira na região sudeste do país.

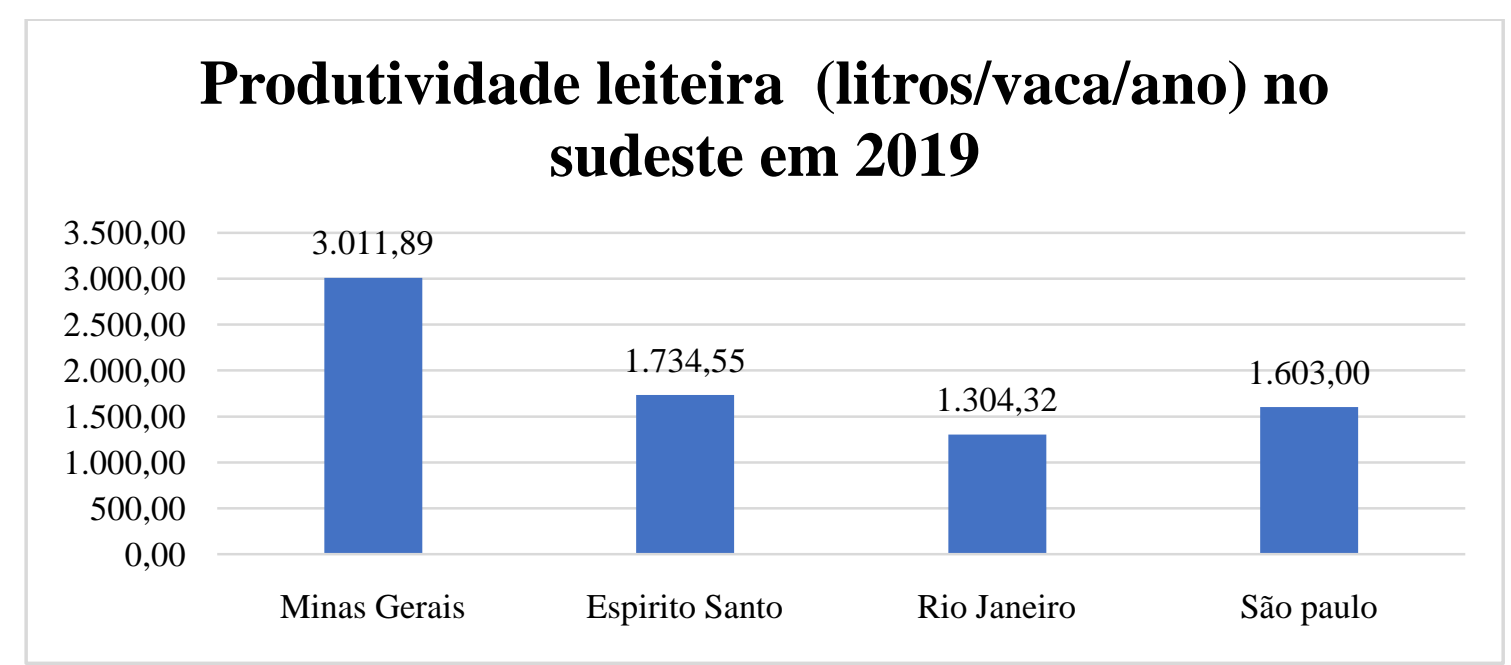

Fonte: Elaboração própria, com base no IBGE.

Na presente atividade, a produtividade do estado do Rio de Janeiro é a menor entre os outros estados. Em 2019 foram produzidos 1.304,32 litros de leite por vaca / ano no estado, ficando com segunda menor produtividade o estado de São Paulo com 1.603 litros. A maior produtividade leiteira foi em Minas Gerais que produziu 3.011,89 litros / vaca, seguido pelo estado do Espirito Santo com uma produtividade de 1.734,55 litro / vaca em 2019.

\section{CONSIDERAÇÕES FINAIS}

A produtividade agrícola do estado do Rio de Janeiro, no contexto da região sudeste, apresentou um forte potencial para evoluir e transformar e economia rural. Já a atividade de pecuária leiteira tem dificuldades que podem e precisam ser melhoradas. É necessário observar tratar-se de um setor econômico importante, em função do número representativo de pessoas envolvidas, ou seja, 178.583 segundo o censo de 2017 (IBGE) e da sua relevância na produção de alimentos. Pode-se afirmar que o setor é muito mais do que atividades estritamente econômicas, já que assume um papel social de extrema relevância, dada a possibilidade de fixar o homem no meio rural, além de sua inserção no trabalho.

O setor agropecuário tem a sua atuação baseada em parâmetros tradicionais de cunho microeconômico, onde são identificados elementos tais como: mercado do tipo oligopsônio, 
unidade produtiva com escala individual, baixo padrão de informação e conhecimento, difícil acesso ao crédito compatível com o negócio, custos altos de produção, informalidade elevada, baixo padrão tecnológico, baixo padrão de produtividade e frágil capacidade competitiva. Mesmo apresentando bom nível de volume de produção, o setor agropecuário no estado do Rio de Janeiro não gera um padrão de riqueza suficiente para projetar o quadro de desenvolvimento regional esperado.

A partir da identificação de gargalos importantes e inibidores do avanço qualitativo do setor, a contribuição aqui apresentada vai no sentido da formulação de um novo modelo operacional nos moldes de uma reestruturação produtiva, o que muda totalmente a natureza dos processos produtivos.

Uma primeira observação é de que a competitividade é primordial em qualquer negócio, já que no sistema capitalista prevalece o mercado. Assim, basear-se nas indicações do modelo neo-endógeno e no novo paradigma rural da OCDE, é essencial para melhor inserção das atividades com o avanço competitivo rural.

Uma segunda observação nos leva a pensar na necessidade de mudança na estrutura produtiva, onde a ação individual deve ser substituída pela ação coletiva. Trata-se de um sistema de organização produtiva a partir da visão de redes, com predominância para a eficiência coletiva e aumento das competências no território. O novo paradigma acentua a figura da governança coletiva como elemento fundamental.

A prática de rede de proteção viabiliza as condições favoráveis para a eliminação dos gargalos já indicados no contexto microeconômico. A participação conjunta entre empresas, governo, universidade e sociedade civil deve ser idealizada e planejada para o fortalecimento do ambiente econômico fragilizado, identificando os recursos tangíveis e intangíveis, elaborando o planejamento e estratégias com foco na produção de produtos e serviços de base no conhecimento e consequente valorização. O olhar sistêmico para o ambiente econômico local / regional, além do global, porém, priorizando o contexto mesoeconômico, é uma alternativa que exige o comprometimento coletivo no processo de absorção do fluxo de capital e na geração de valor para a economia local (RIBEIRO E HASENCLEVRE, 2019).

Essa complexa estrutura, entretanto, exige "Capital Social", elemento que molda o desempenho das instituições sociais de acordo como os atores confiam uns nos outros. Segundo Putnam (2005), esse comportamento de cooperação e regras de reciprocidades tende a superar os dilemas coletivos nas comunidades cooperativas. 
Portanto, a reflexão sobre o novo paradigma rural da OCDE e o aprofundamento da discussão sobre desenvolvimento endógeno e neo-endógeno se constitui na alternativa viabilizadora de economia rural com maior autonomia de riqueza para o estado.

\section{REFERÊNCIAS}

BICZKOWSKI, Mirosław. LEADER as a mechanismofneo-endogenousdevelopmentof rural areas: the case ofpoland. MiscellaneaGeographica, [S.L.], v. 24, n. 4, p. 232-244, 1 out. 2020. Walter de GruyterGmbH. http://dx.doi.org/10.2478/mgrsd-2020-0041. Disponível em: https://sciendo.com/article/10.2478/mgrsd-2020-0041. Acesso em: 04 mar. 2021.

GKARTZIOS, M., LOWE, P. Revisiting Neo-Endogenous Rural Development, in: Scott, M., Gallent, N. and Gkartzios, M. (eds). The Routledge Companion to Rural Planning, Routledge: New York, 2019.

IBGE - Instituto Brasileiro de Geografia e Estatística. Disponível em: https://petrobras.com.br/pt/quem-somos/plano-estrategico/. Acesso em 10 abr. 2021.

KIM, Tae-Yeon.A Study on Reasons of Development Gap in Rural Community Development: The Application of Neo-Endogenous Development. Korean J. Org. Agric. v. 28, n. 1: 69-93, 2020.

LOWE, P., C. RAY, N. Ward et al. Participation in rural development: a review of European experience. Centre for Rural Economy, Universityof Newcastle, Newcastle, England, 1998.

NAZARETH, P., ARAÚJO, N. e OLIVEIRA, H. O Rio de Janeiro e as rendas petrolíferas: a crise e os desafios do pré-sal, in Transformação em curso na Indústria Petrolífera Brasileira. Piquet, Rio de Janeiro: E-Papers Serviços Editoriais Ltda, [2---?].

NUPERJ - Núcleo de Pesquisa Econômica do Rio de Janeiro. Disponível em: https://uenf.br/projetos/nuperj/. Acesso em: 10 abr. 2021.

OECD - Organisation for Economic Co-operation and Development Rural 3.0: People Centred Rural Policy- Policy Highlights, 2019.Disponívelem:

OECD - Organisation for Economic Co-operation and Development. The New Rural Paradigm.Paris: OECD publishing, 2006.

OSTI, G. LEADERand partnerships: the case of Italy. Sociologia Ruralis v. 40, n. 2, p. 172180.

PETROBRAS. Disponível em: https://petrobras.com.br/pt/quem-somos/plano-estrategico/. Acesso 02 abr. 2021.

PUTNAM, R. Comunidade e Democracia: A Experiência da Itália Moderna. 4.ed. Rio de Janeiro: FundaçãoGetúlio Vargas, 2005. 
RAY, C. Towards a theory of the dialectic of local rural development within the European Union. Sociologia Ruralisv. 37, n.3, p. 345-362.

RIBEIRO, Alcimar, HASENCLEVER, Lia.Investigação sobre a capacidade de absorção de externalidades positivas geradas por grandes projetos no estado do Rio de Janeiro. Rev. Econ. NE, Fortaleza, v. 50, n. 2, p. 133-145, 2019.

RIBEIRO, Alcimar e MAROUVO, C. Aprendizado com a Pandemia de COVID-19 para Além dos Paradoxos Dogmáticos: o Pragmatismo Local /Regional. Revista de Extensão da UENF.v. 5. n.1, 2020.

SHORTALL, S.Are rural development programmes socially inclusive? Social inclusion, civic engagement, participation, and social capital: exploring the differences. Journal of Rural Studies v. 24, n. 4, p. 450-457, 2008.

WOODS, M. Rural Geography.Sage: London, 2005. 